\title{
Segregación residencial y fragmentación urbana: los fraccionamientos cerrados en Guadalajara
}

Luis Felipe Cabrales Barajas ^ Elia Canosa Zamora ${ }^{\star+}$

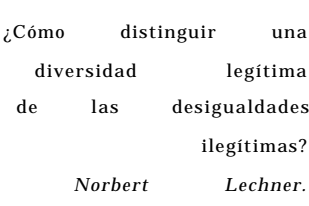

El presenteensayo aborda el fenómeno de los fraccionamientos cerrados en Guadalajara. Sehaceuna revisiónhistórica para mostrar sus antecedentes. También se revisa el estado de la cuestión, identificando obras que documentanel fenómenoenvarios países deAmérica. Se realiza un intento de definición de los costos cerradosysedescribesu presencia

enlaZona Conurbada deGuadalajara, proponiendo un debate sobre sus significados sociales ysu impactoenla estructuración de la ciudad, lo cual implica analizarlas relaciones público-privado.

- Departamento deGeografíayOrdenación Territorial del CUCSH-UdeG. ccf41363@fuentes.csh.udg.mx $\hookrightarrow$ Departamento de Geografía de la Universidad Autónoma de Madrid. Un convenio de colaboración entre ambas universidades permitióa la Dra. Elia Canosa Zamora realizaruna estancia de investigaciónen Guadalajara durante 1995.

elia.canosa@uames con dos por grupos étnicos minoritarios. Según algunas interpretaciones, dichos sectores marginales tienen un carácter "residual" o “indeseable" y definen su territorialidad mediante la configuración de ghettos o slums.

En las ciudades latinoamericanas, tal fenómeno se relaciona con la pobreza, antes que con la diferencia étnica. Al manifestar rasgos distintivos parecería que esos grupos no se adaptan al concepto dominante de ciudad, según códigos formalmente establecidos por la legislación y los patrones culturales que intentan imponerse.

Las partes marginales de las ciudades latinoamericanas (identifica- 


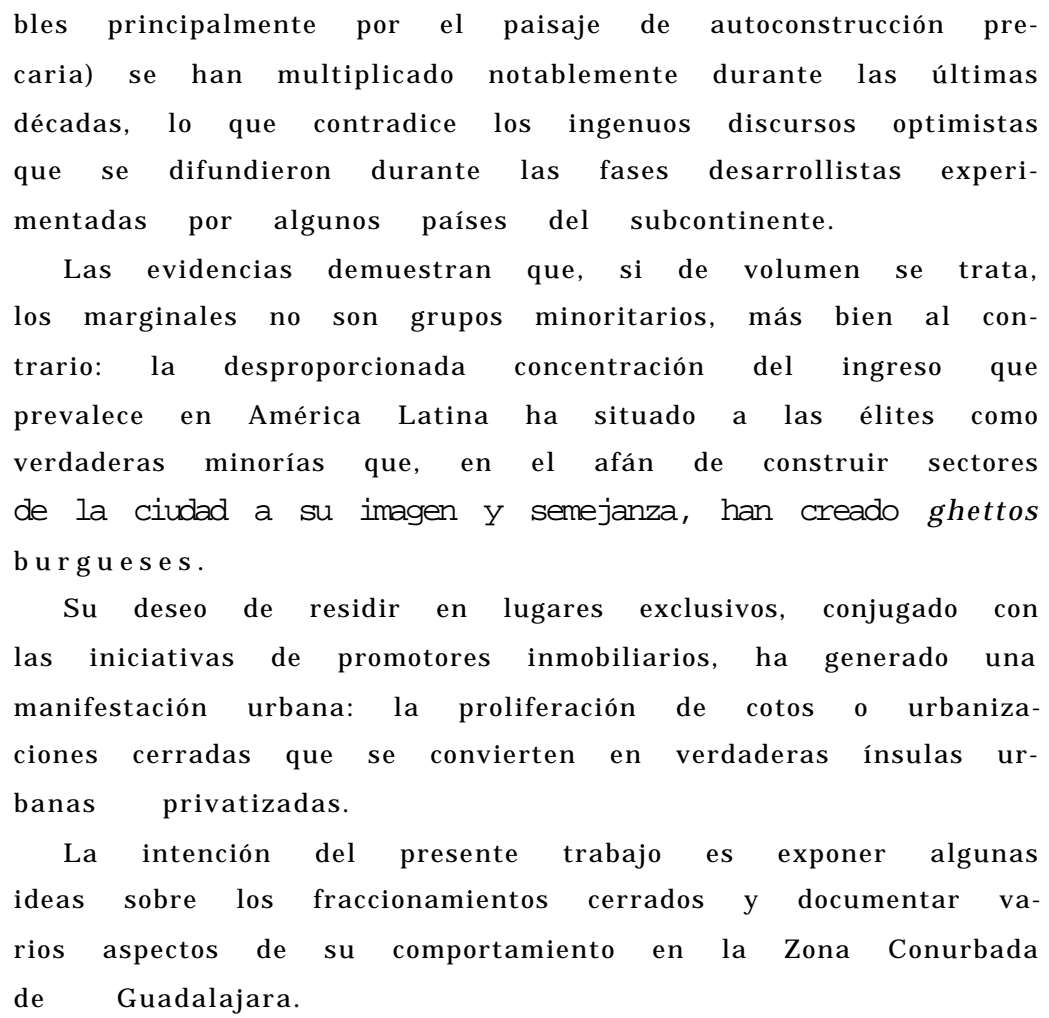

\section{Guadalajara:unsiglo debúsqueda de exclusividad urbana en tres episodios}

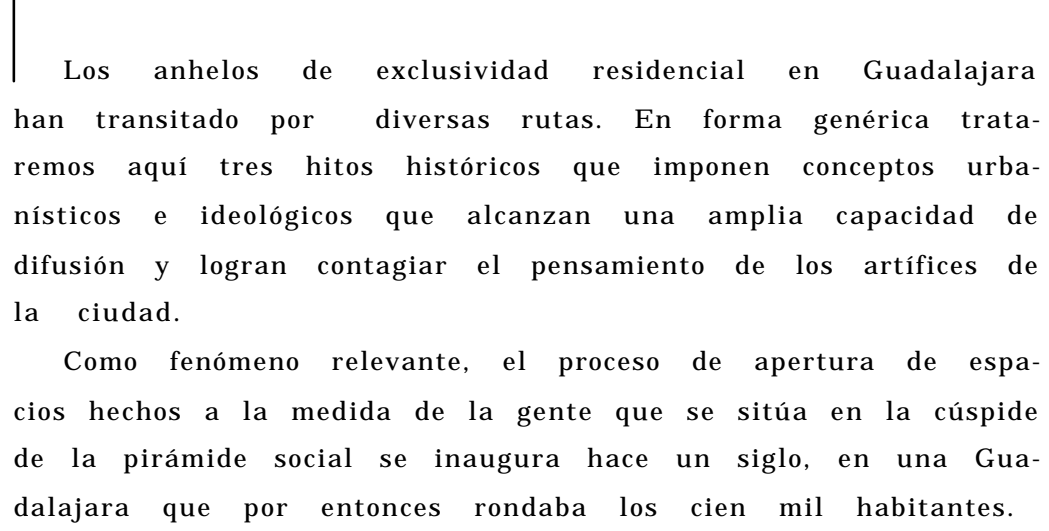




\section{Segregaciónresidencialyfragmentaciónurbana}

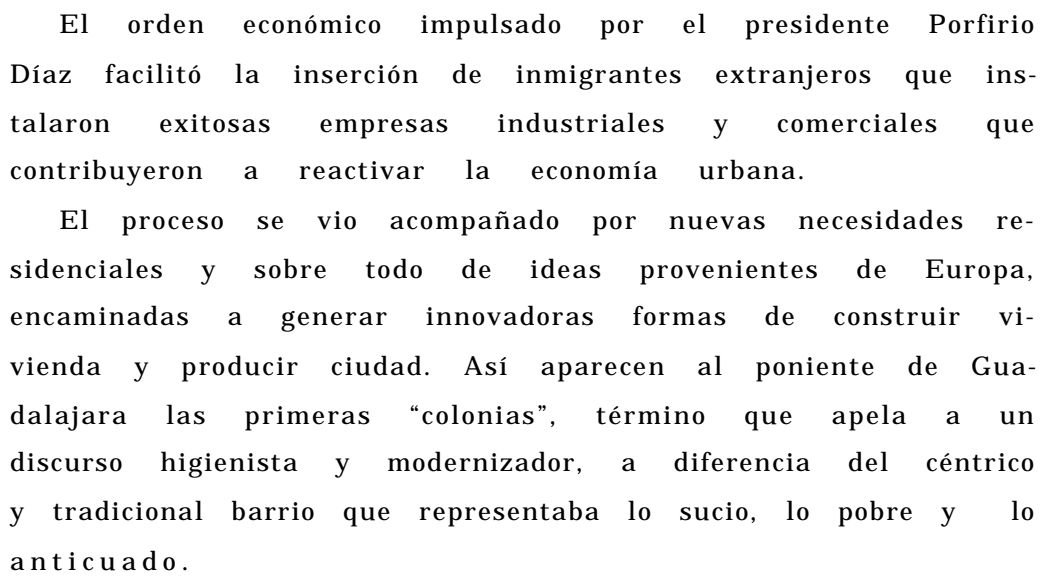

El proceso se vio acompañado por nuevas necesidades residenciales y sobre todo de ideas provenientes de Europa, encaminadas a generar innovadoras formas de construir vivienda y producir ciudad. Así aparecen al poniente de Guadalajara las primeras "colonias", término que apela a un discurso higienista y modernizador, a diferencia del céntrico y tradicional barrio que representaba lo sucio, lo pobre y lo anticuado.

Al amparo de influencias urbanísticas de Jorge Eugenio Haussmann (París) e Ildefonso Cerda (Barcelona), los modernos promotores inmobiliarios de la época contribuyen a fundar un fenómeno de diferenciación que tenía como objetivo generar espacios urbanos no para integrarse a la ciudad preexistente, sino separarse de ella con el propósito de conservar atributos diferenciales acordes con la posición social de sus residentes, un proyecto reformista que logró consolidarse y formar un ensanche urbano que con sus áreas verdes, amplias calles y opulentas mansiones intentaba emular el de sus contrapartes europeas.

El lenguaje arquitectónico y la morfología de las casas tenia un correlato con las innovaciones urbanas: se levantan fincas que enaltecen sus pretensiones señoriales gracias a los jardines circundantes que amplían el horizonte visual. Se va trazando así un paisaje urbano análogo al de ciudades europeas y estadounidenses y que se aleja del modelo español -de origen andaluz- de la Guadalajara colonial, mismo que optaba por patios interiores $y$ alineamientos cerrados de fachadas.

López Moreno (1996:226) considera que "Ias nuevas colonias" son el fruto de un proyecto excluyente: "Intentan separar orgánica y socialmente hablando, creando una unidad 


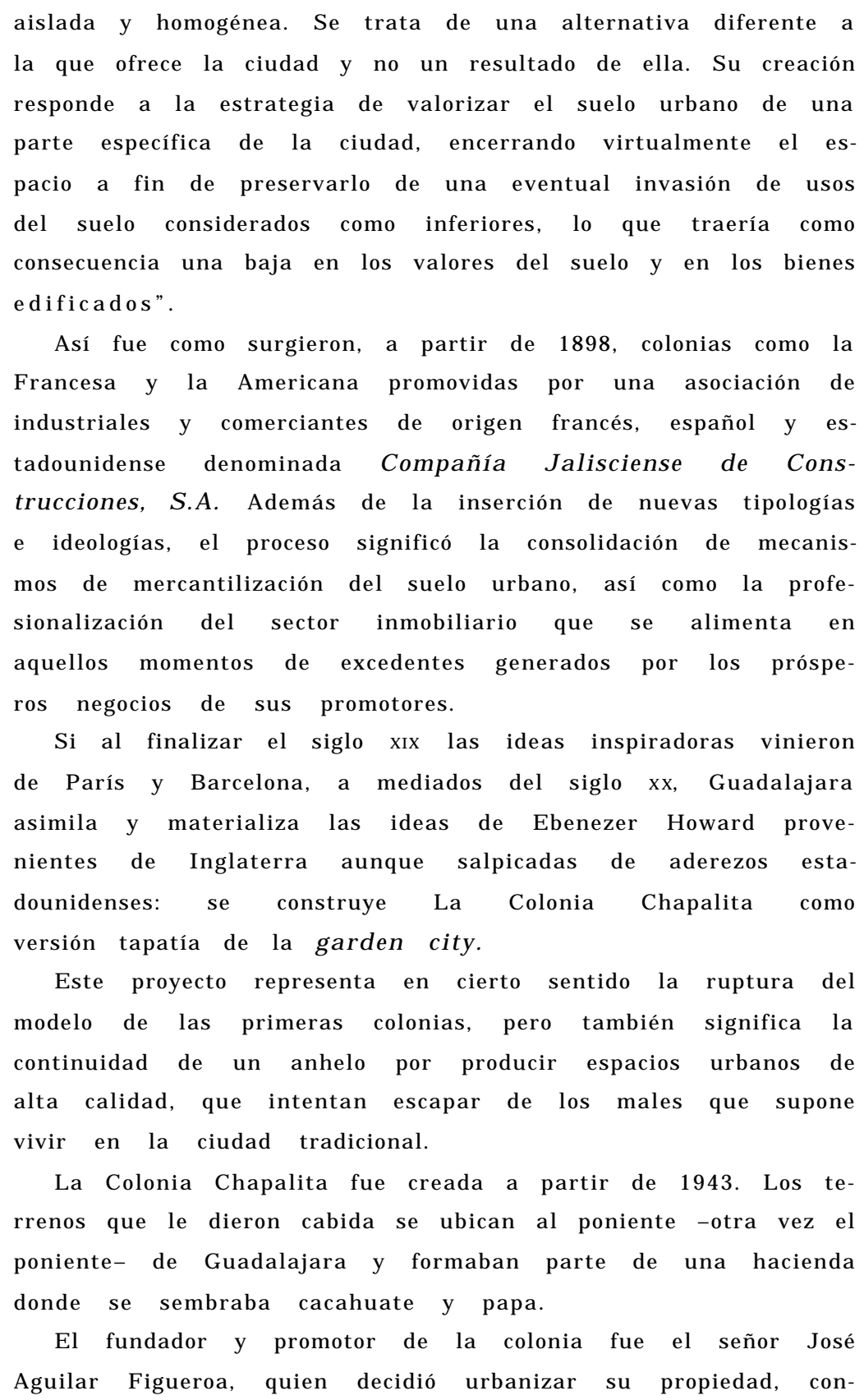




\section{Segregaciónresidencialyfragmentaciónurbana}

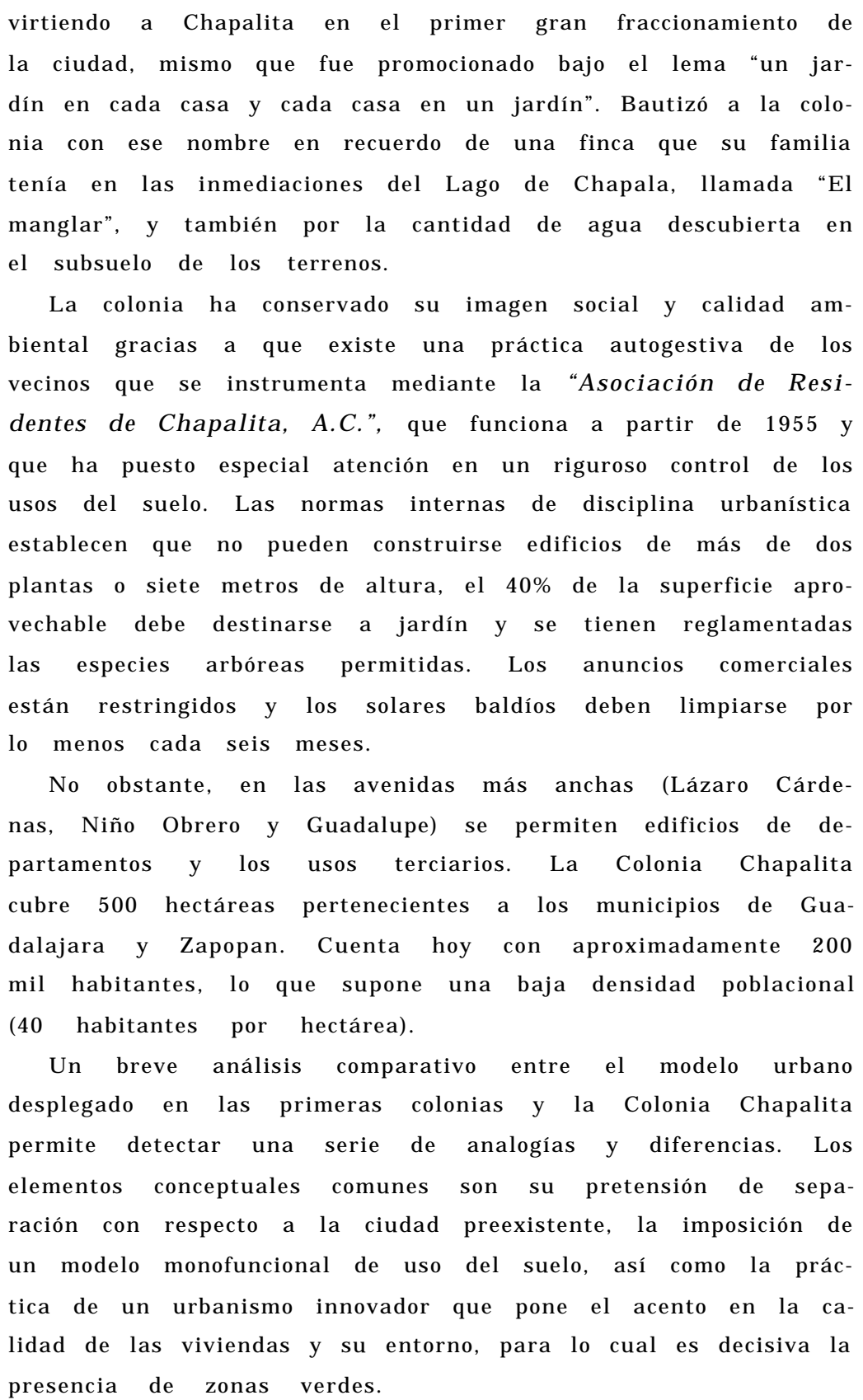




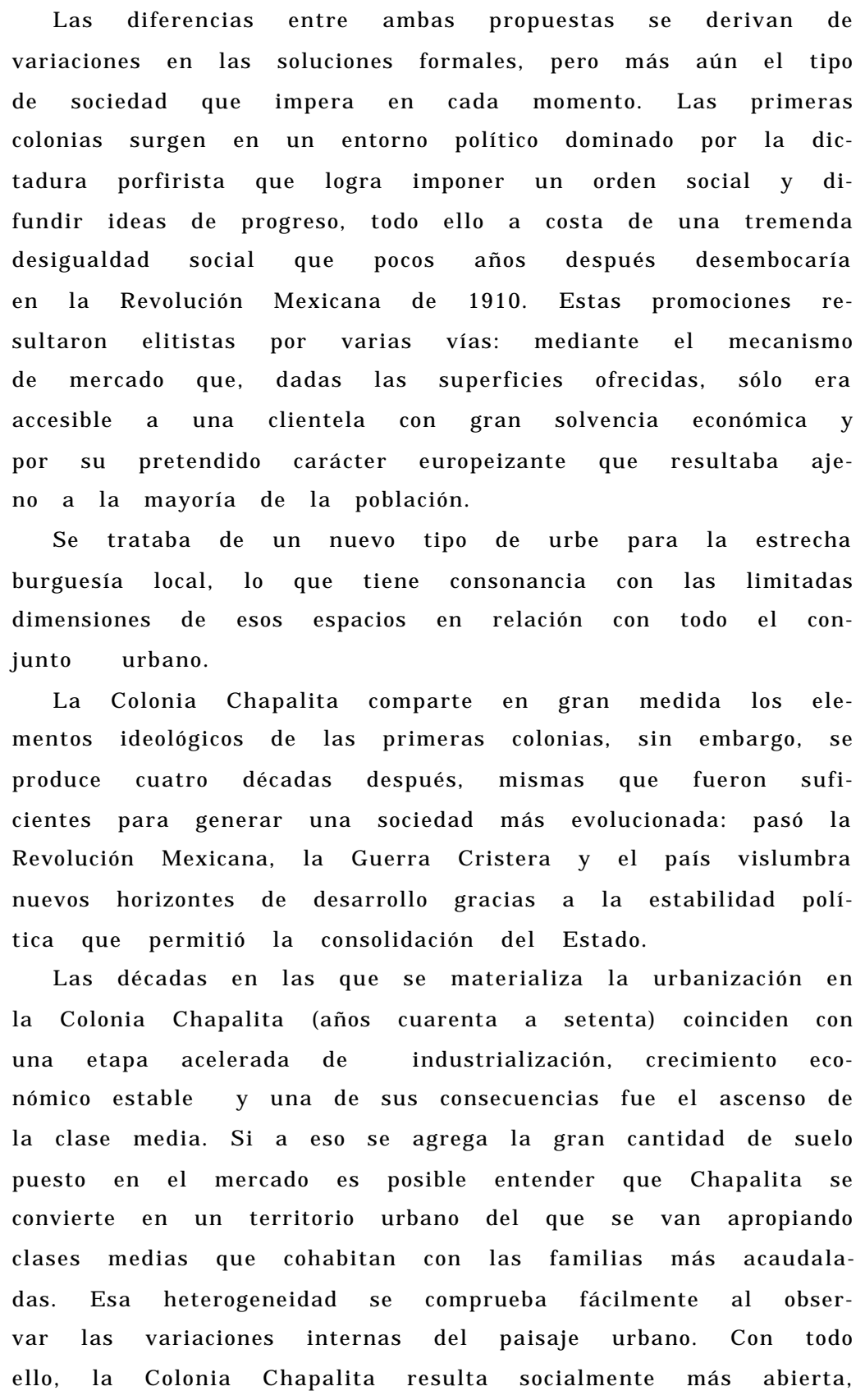


Segregaciónresidencialyfragmentación urbana

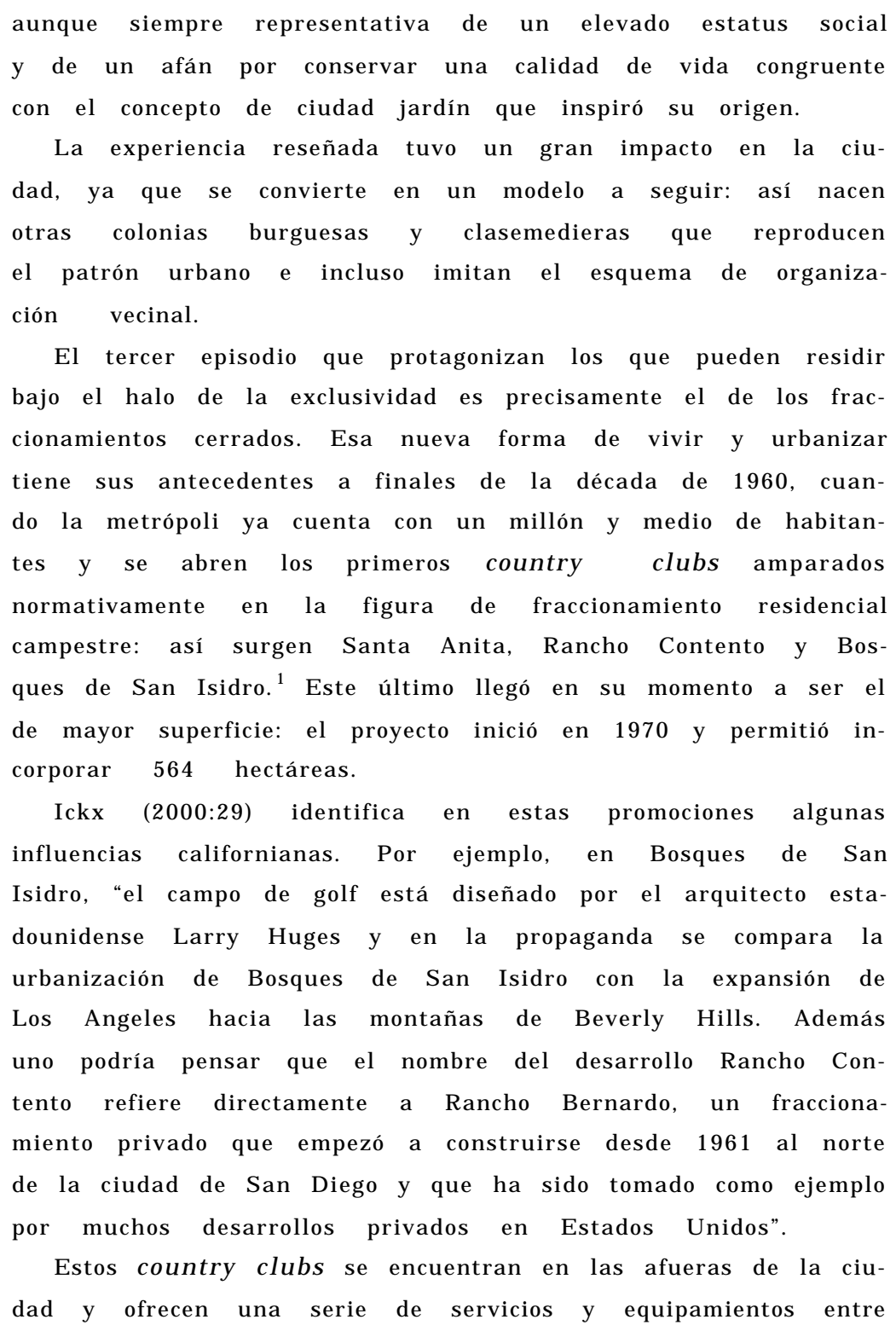

El tercer episodio que protagonizan los que pueden residir bajo el halo de la exclusividad es precisamente el de los fraccionamientos cerrados. Esa nueva forma de vivir y urbanizar tiene sus antecedentes a finales de la década de 1960, cuando la metrópoli ya cuenta con un millón y medio de habitantes $y$ se abren los primeros country clubs amparados normativamente en la figura de fraccionamiento residencial campestre: así surgen Santa Anita, Rancho Contento y Bosques de San Isidro. ${ }^{1}$ Este último llegó en su momento a ser el de mayor superficie: el proyecto inició en 1970 y permitió incorporar 564 hectáreas.

Ickx (2000:29) identifica en estas promociones algunas influencias californianas. Por ejemplo, en Bosques de San Isidro, “el campo de golf está diseñado por el arquitecto estadounidense Larry Huges y en la propaganda se compara la urbanización de Bosques de San Isidro con la expansión de Los Angeles hacia las montañas de Beverly Hills. Además uno podría pensar que el nombre del desarrollo Rancho Contento refiere directamente a Rancho Bernardo, un fraccionamiento privado que empezó a construirse desde 1961 al norte de la ciudad de San Diego y que ha sido tomado como ejemplo por muchos desarrollos privados en Estados Unidos".

Estos country clubs se encuentran en las afueras de la ciudad $y$ ofrecen una serie de servicios $y$ equipamientos entre

1 LaLeyEstatal deFraccionamientos de 1969 establece en suartículo 7ㅇla figura defraccionamiento habitacional campestre. Menciona entre otras nomas que la superficiemínima de los terrenos deberá ser de 800 metros cuadrados. 
los que no falta el campo de golf. Es posible que, en una primera etapa, la función habitacional haya sido a tiempo parcial, ya que las familias propietarias las utilizaban como residencias secundarias durante fines de semana y periodos de asueto. Posteriormente se convierten en viviendas permanentes, toda vez que se incrementan las condiciones de accesibilidad rápida y se revaloran sus ventajas con respecto al resto de la ciudad, que por cierto se extiende lo suficiente para casi alcanzar a estos fraccionamientos.

La ciudad que ve desplegar los fraccionamientos cerrados es ya una gran metrópoli en la que se rompe la escala humana y se desbordan los problemas de segregación social, inseguridad pública y deterioro ambiental. También se produce una retracción de la clase media y por consecuencia se incrementa la polarización del tejido social.

\section{Laciudadblindada: breveestado}

de la cuestión y definición de

los fraccionamientos cerrados

El fenómeno de los fraccionamientos cerrados sorprende por dos aspectos contradictorios: se trata de un fenómeno relevante, creciente y de alto impacto en la estructuración de las ciudades y a pesar de ello ha sido poco estudiado. ${ }^{2}$ Esto corrobora la afirmación de que "no existe una relación lineal entre las realidades urbanas de determinada sociedad y la producción de conocimiento existentes en ella" (Kowarick, 1992:12).

A través de la exploración bibliográfica y de contactos directos hemos identificado algunos trabajos de investigación al respecto. Suárez (1997) publicó un sugerente texto en el

2Tal como lo señala Pesci (1996:823), enArgentina se ha producido ungran debate en tomo a los barrios cerrados, situación que no ha ocurido en otros países como México, donde la discusión se restringe al mundo académico yno logra todavía trascendera la esfera pública. 


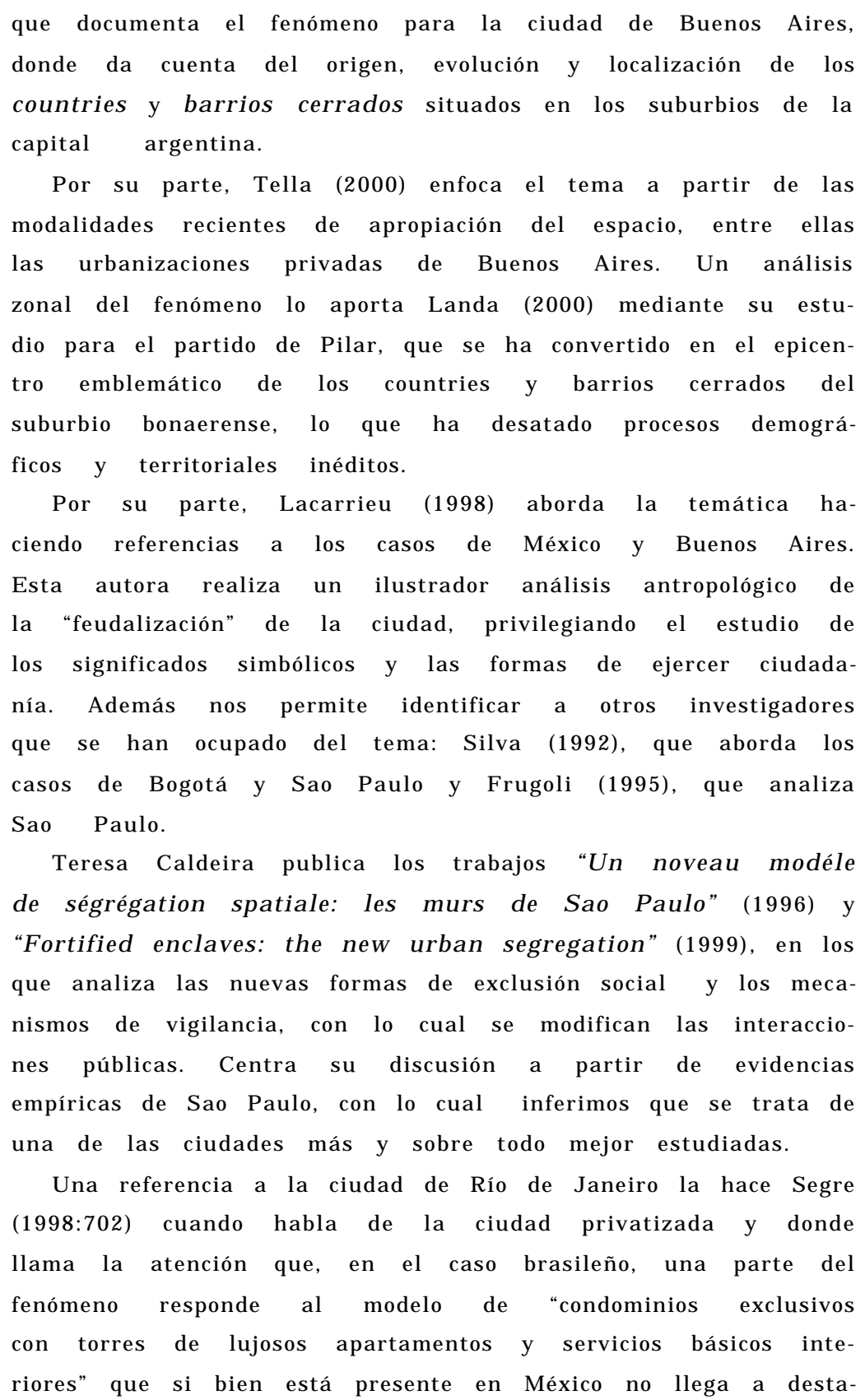


car, puesto que domina el modelo horizontal. ${ }^{3}$ Valladares y Jacot (1999:29) dan noticia de la existencia de "la otra Brasilia", la ciudad cerrada que se forja so pretexto de la violencia y la inseguridad.

Conocemos también el texto de Safa (1999) para la ciudad de México que, al igual que el de Lacarrieu, tiene una orientación antropológica. Ickx hace aportaciones al estudio de los fraccionamientos cerrados en Guadalajara, que entre otras novedades contiene una exploración bibliográfica sobre las repercusiones de los fraccionamientos cerrados en ciudades de Estados Unidos, destacando la obra City of Quartz, excavating the future in Los Angeles, de Mike Davis. El autor se adentra en analizar la dualización sociourbana de Los Angeles: "Vivimos en ciudades-fortalezas divididas brutalmente entre las células fortificadas de la sociedad opulenta y lugares de terror donde la policía lucha en contra de los pobres criminalizados" (1990:224).

Otra aportación es Privatopia, homeowner associations and the rise of residential private government (McKenzie: 1994), obra pionera que analiza las estrategias de las agencias inmobiliarias y de planeación urbana en torno a los fraccionamientos cerrados e incluso analiza la posibilidad de que los gobiernos privados de estas comunidades lleguen en un momento a suplir a los órganos municipales.

Por su parte, en Fortress America, gated communities in the United States ( Blakely y Snyder:1997) se analizan distintas dimensiones de los fraccionamientos cerrados y se identifican diversas tipologías de recintos urbanos fortificados.

3Esta tipología está asociada conel concepto de "torre jardín"quees definida porTella (2000:8): "Se trata de edificios de departamentos, destinados a residenciapermanente, localizados sobreáreas residenciales densamenteconsolidadasy senvidas. Son torres de gran altura, de perímetro libre, con volúmenes muyelaborados, cuyo predio ocupa generalmentela totalidad dela manzana (una hectárea) eincluyen un departamento por planta, degrandes dimensiones (más de 200 metros cuadrados), capaz de competir con la residencia individual. Tienen un cerco de protección con custodia pemanente y plantas bajas provistas de servicios e infraestructura de uso exclusivo". 


\section{Segregaciónresidencialyfragmentaciónurbana}



A pesar de que la documentación es limitada permite aventurar algunas hipótesis de trabajo. Es posible afirmar que se trata de un hecho urbano con fuerte presencia en el continente americano: resulta necesario indagar las influencias explícitas que Estados Unidos ejerce sobre América Latina. Por mencionar un ejemplo, Segre establece las repercusiones del urbanismo de Miami sobre Río de Janeiro, concretamente en la Barra de Tijuca (1998:702).

La búsqueda de analogías entre la ciudad estadounidense y la ciudad latinoamericana puede resultar esclarecedora. En su magistral caracterización de La Ciudad Posmoderna (2000), Amendola le da un peso relevante al tema del miedo y las estrategias de defensa desplegadas por "el ciudadano atemorizado que busca vivir en una burbuja protectora" (ídem: 318), lo cual Ileva a construir la "ciudad blindada". El autor considera el crimen, pero más aún, el miedo al crimen, como elementos que “impulsan a la fortificación física y electrónica del territorio, al punto que un tercio de las nuevas comunidades de California meridional están protegidas electrónicamente" (ídem:316).

Amendola contrapone dos modelos de seguridad ciudadana; el europeo, en donde "la ciudad - a pesar de sus contrastes internos- ha permanecido siempre única gracias a una 


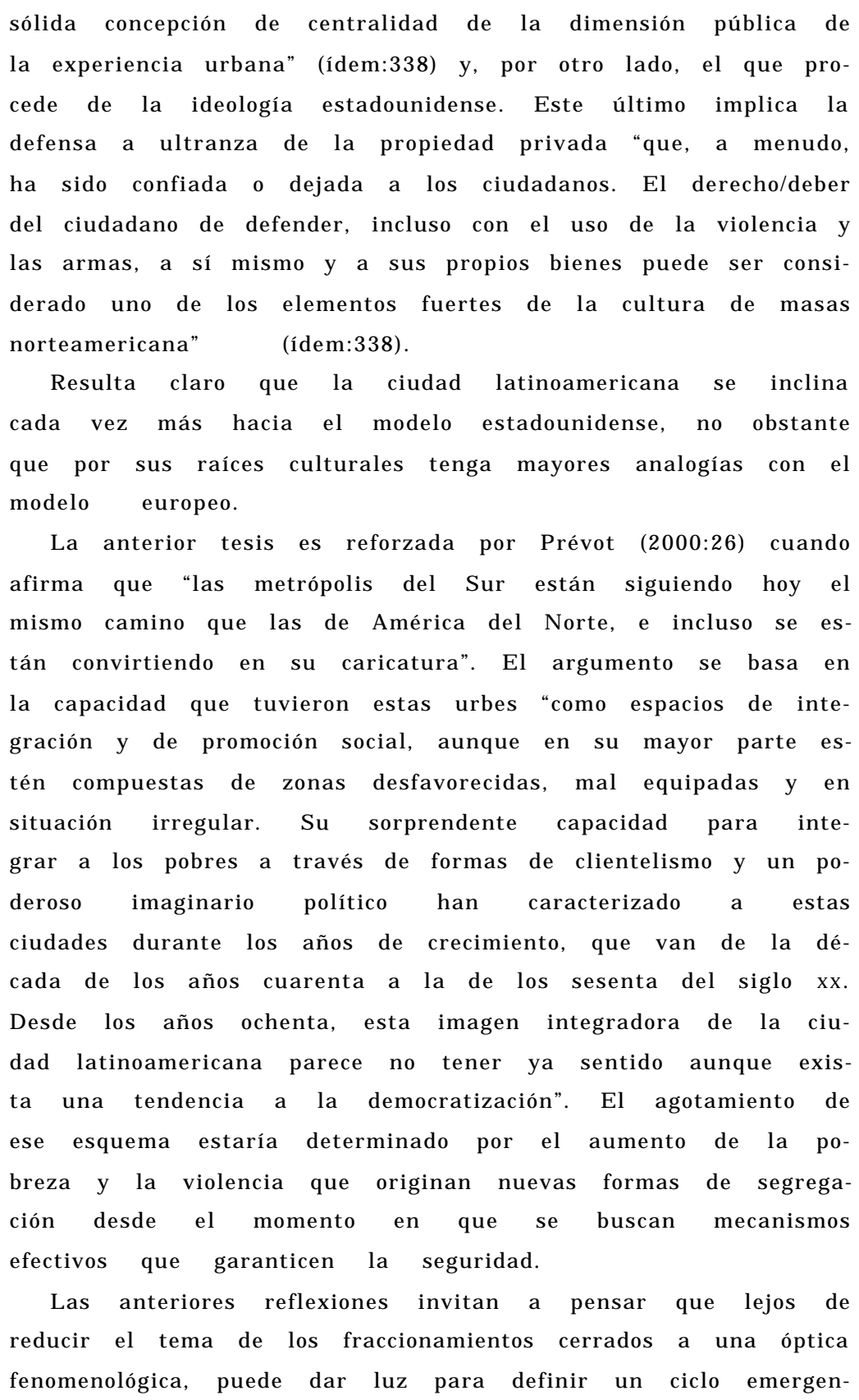




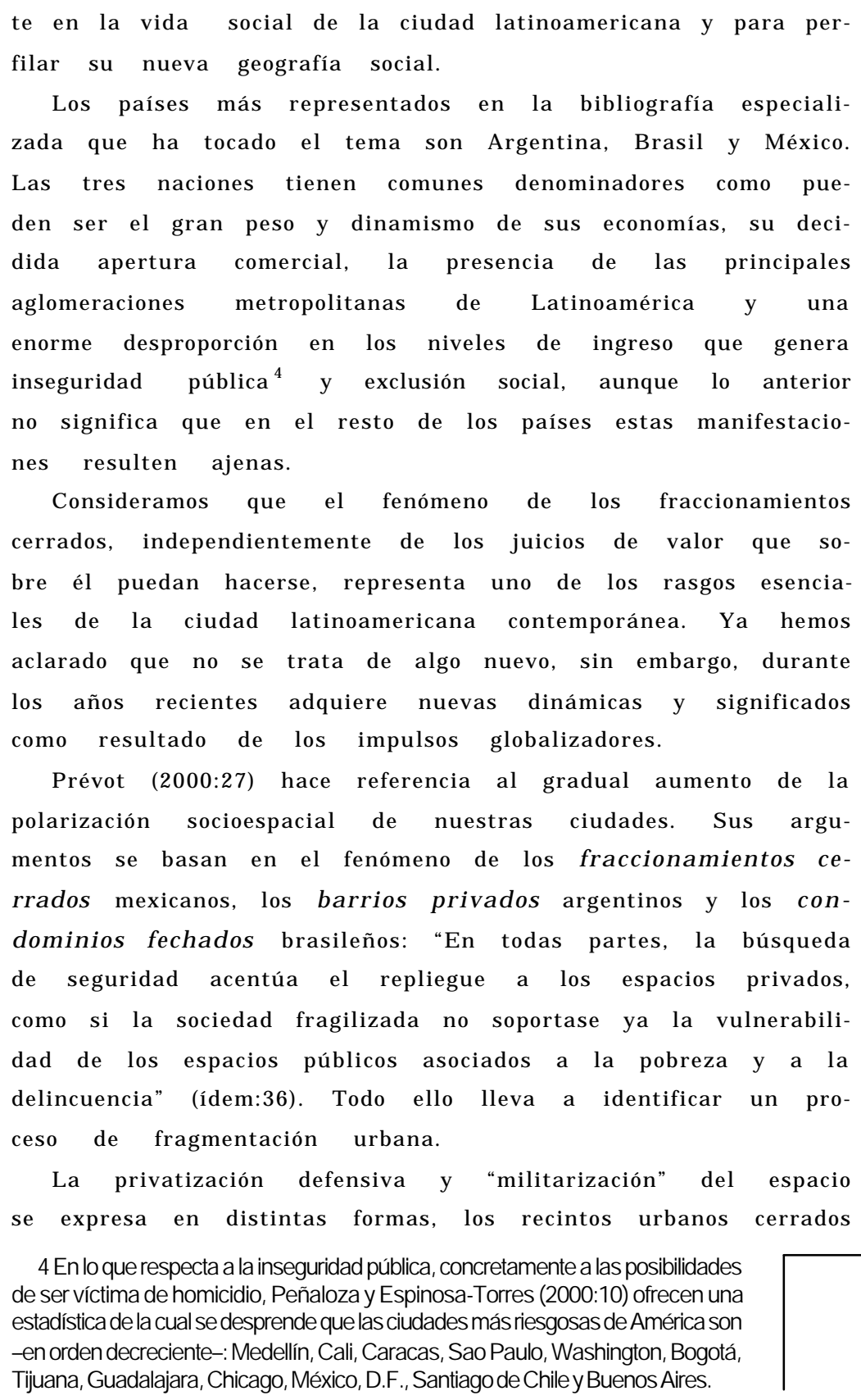

4En lo que respecta a la inseguridad pública, concretamentea las posibilidades de ser víctima de homicidio, Peñaloza y Espinosa-Torres (2000:10) ofrecen una estadística dela cual se desprende quelas ciudades más riesgosas deAmérica son -enorden decreciente-: Medellín, Cali, Caracas, Sao Paulo, Washington, Bogotá, Tijuana, Guadalajara, Chicago, México, D.F.,Santiago deChileyBuenosAires. 


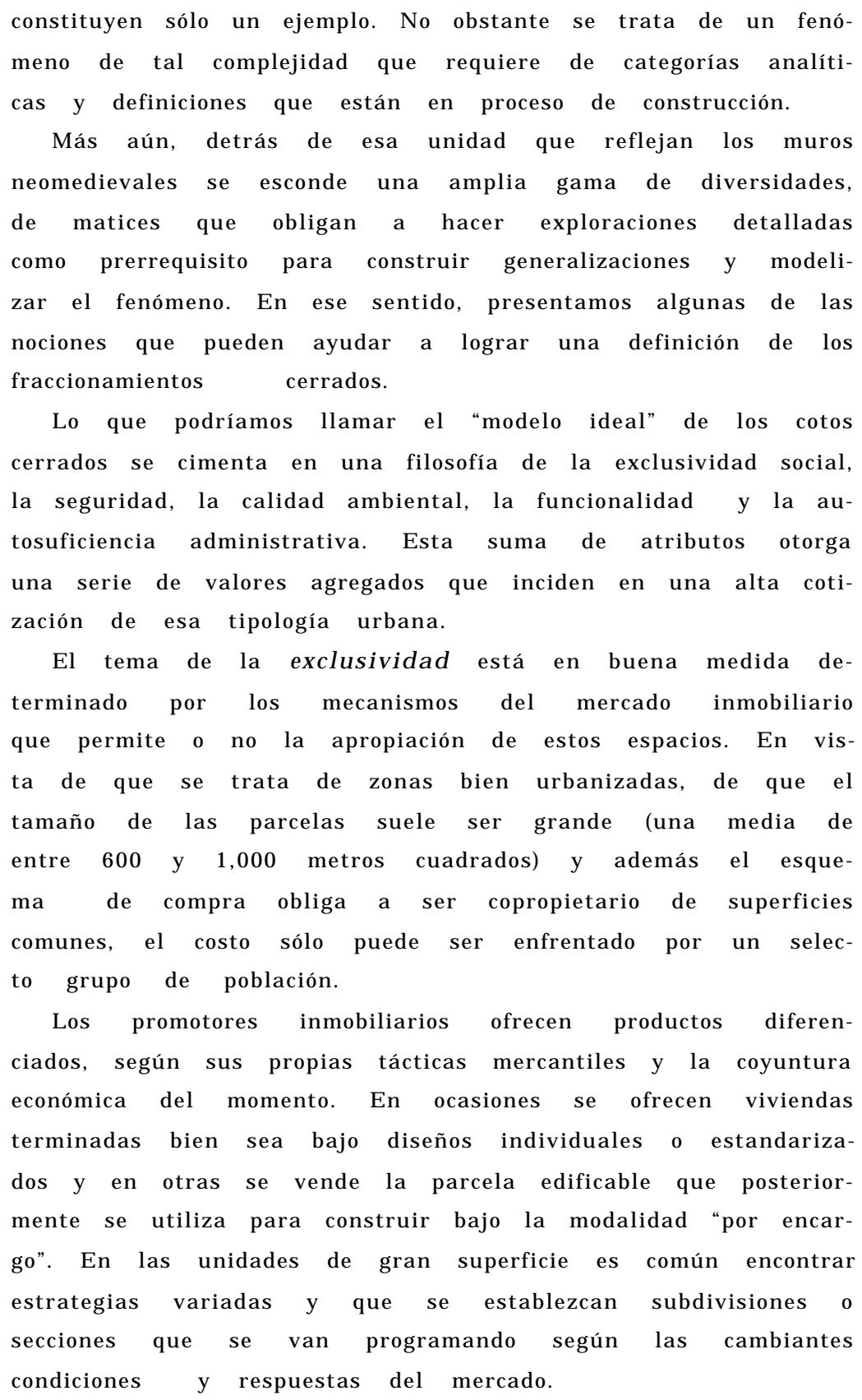


Segregaciónresidencialyfragmentación urbana

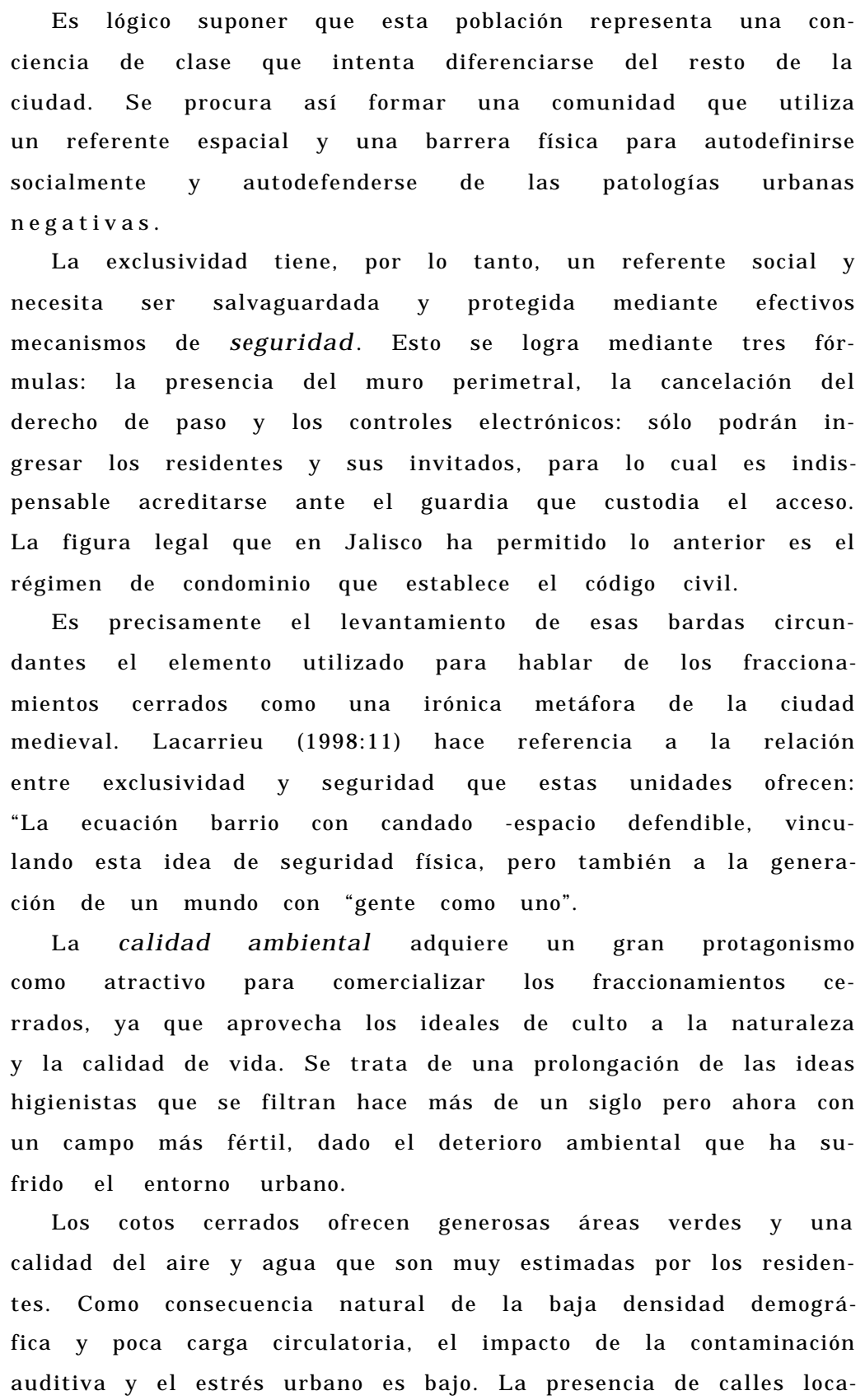




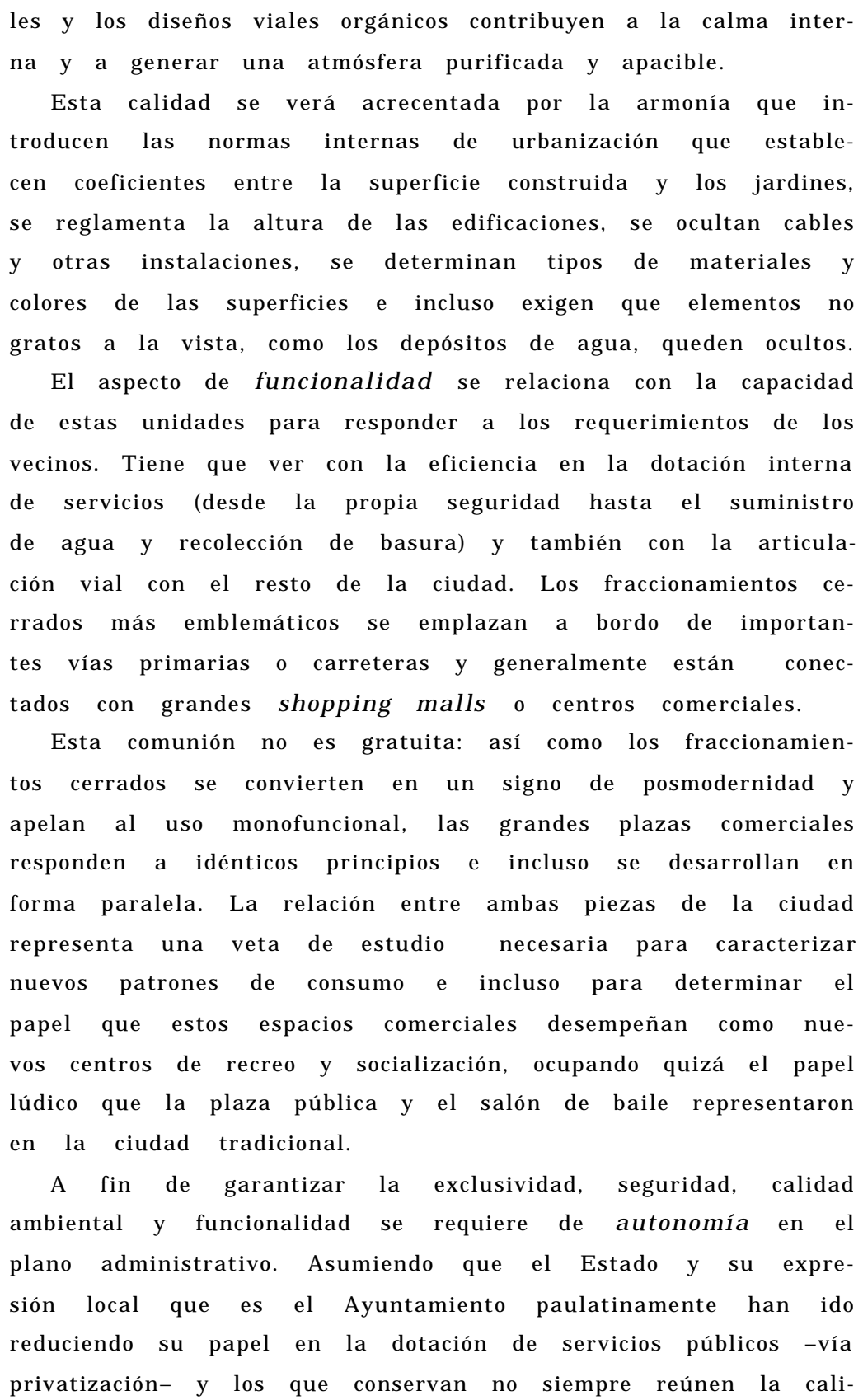




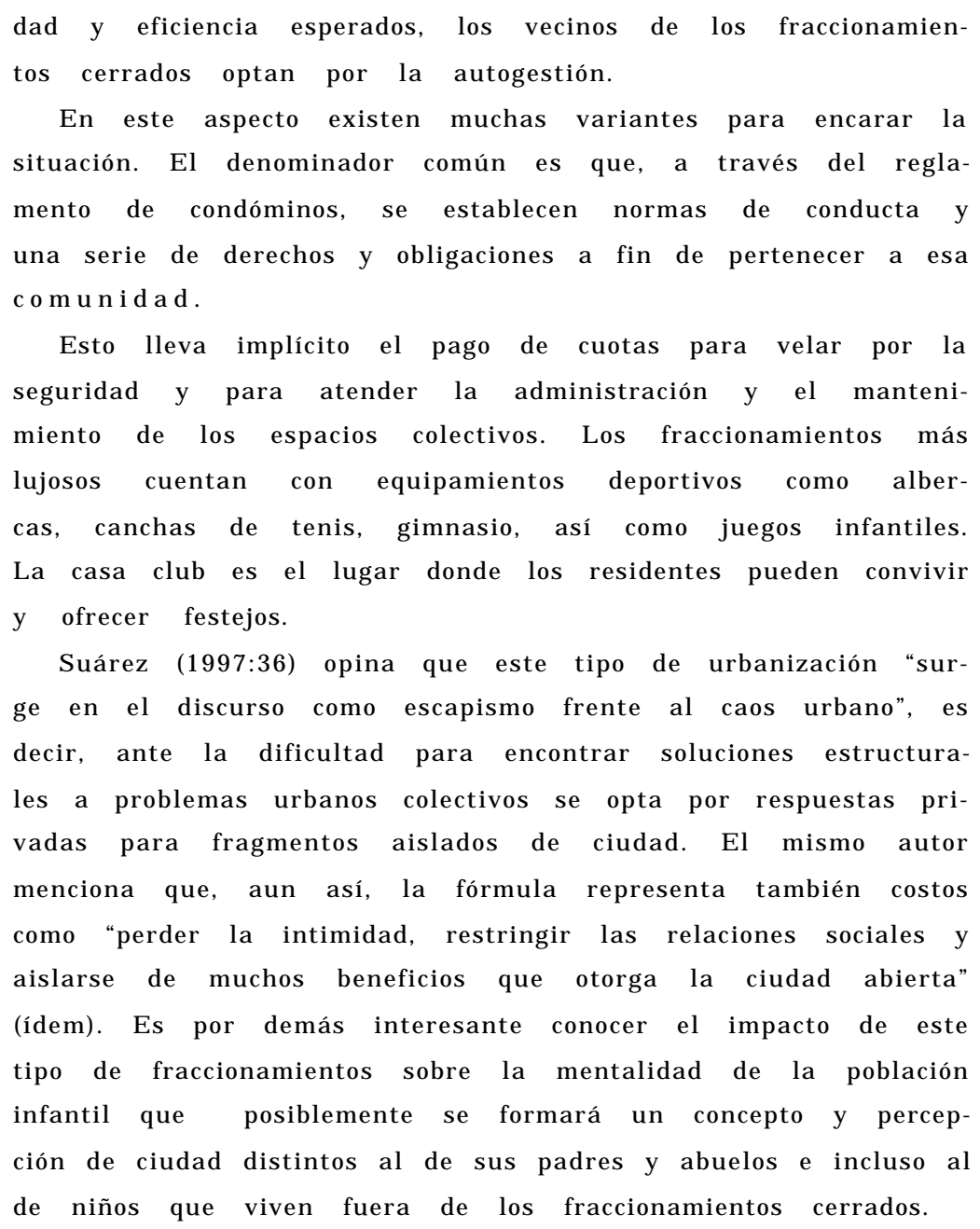

Los fraccionamientos cerrados en Guadalajara: el diez por ciento del tejido urbano

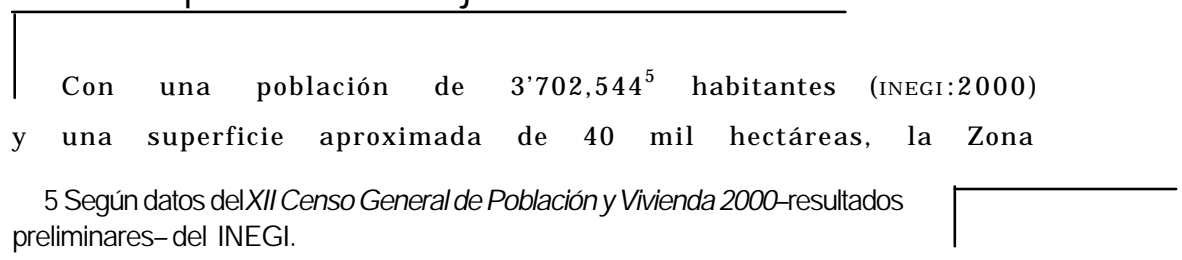




\section{Luis FelipeCabrales Barajas yElia Canosa Zamora}

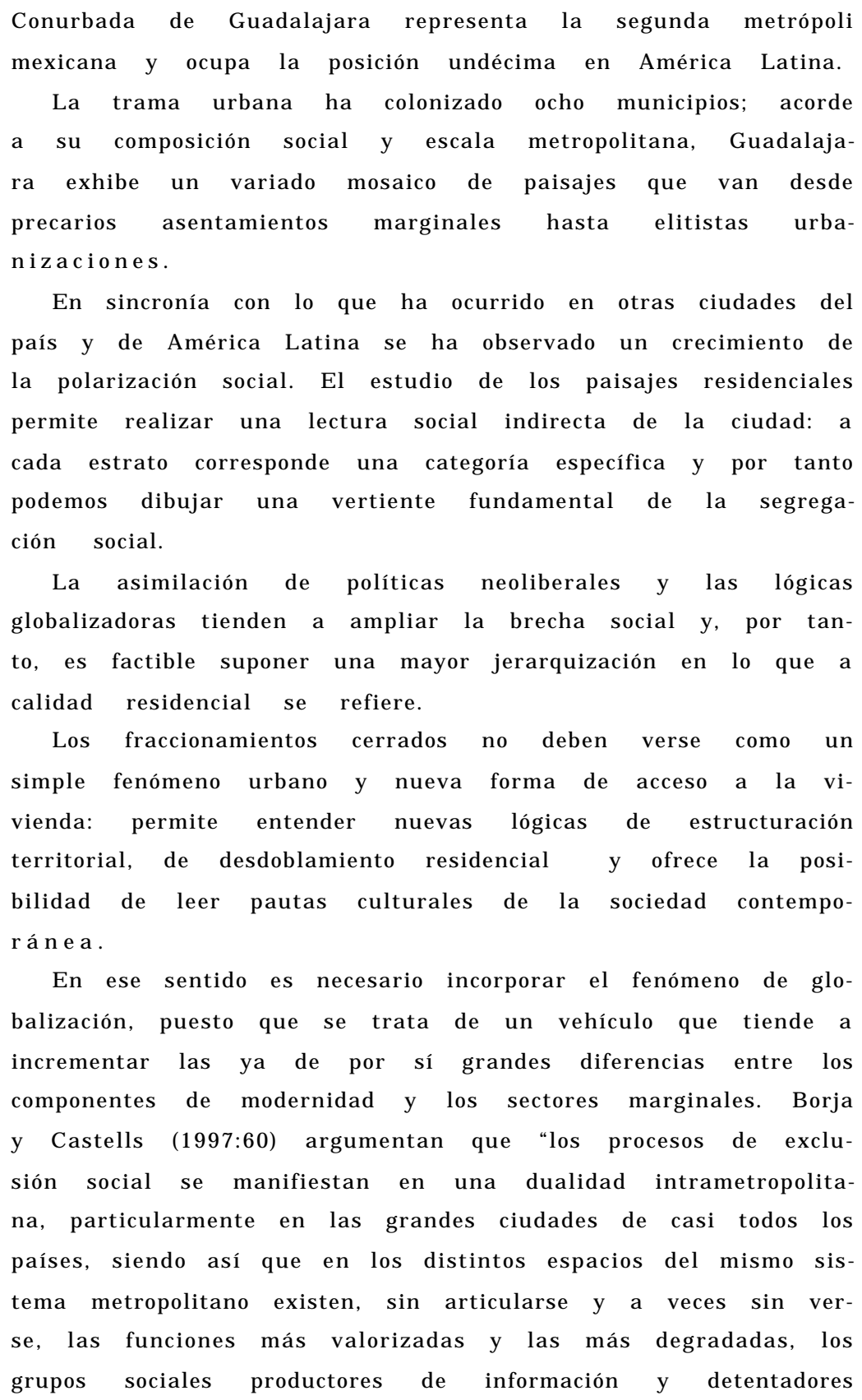




\section{Segregaciónresidencialyfragmentaciónurbana}

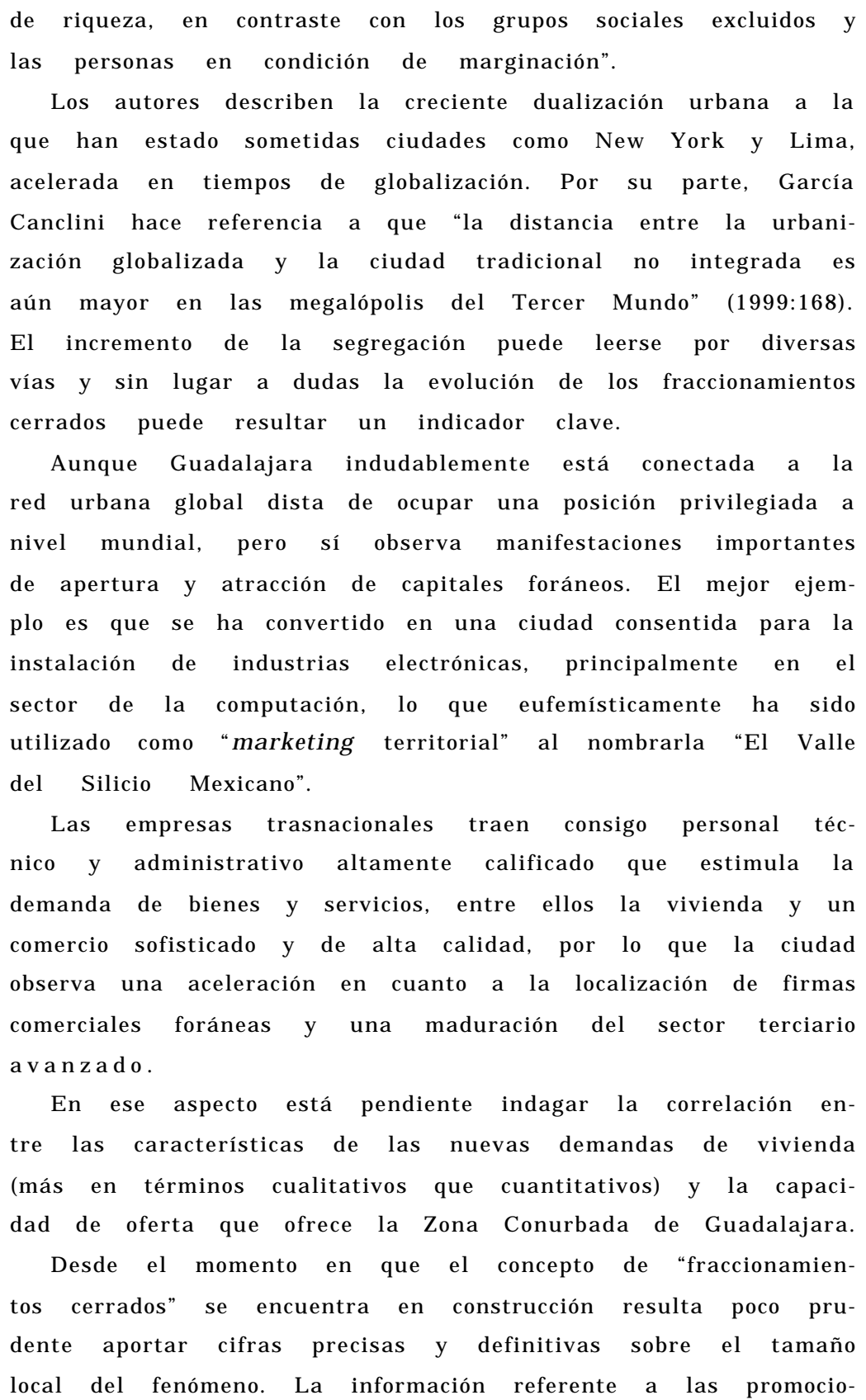


nes inmobiliarias siempre es difícil de documentar y en este caso se complica porque no es sencillo suplir carencias mediante trabajo de campo o entrevistas, dado el hermetismo simbólico y físico de dichos espacios.

No obstante esas limitaciones, es necesario un intento de aproximación. Para el año 1996 inventariamos 21 fraccionamientos cerrados en la Zona Conurbada de Guadalajara, mismos que cubrían una superficie próxima a las tres mil hectáreas y había dado cabida a 15 mil lotes y 60 mil personas. ${ }^{6}$

Aunque estemos ante cifras redondeadas y por tanto inexactas, es posible hacer un balance preliminar. En términos de superficie supondría que, para esa fecha, ocupaban casi el $10 \%$ del tejido urbano pero apenas albergaban al $2 \%$ de la población. Como derivación lógica de lo anterior tendríamos que los cotos cerrados observan una densidad próxima a las 20 personas por hectárea, que resulta muy baja si se compara con el promedio metropolitano que ronda las 100 personas.

Durante los años recientes se observa una tendencia a reducir el tamaño de las promociones. ${ }^{7}$ Esta situación puede estar relacionada con la crisis económica experimentada durante los años 1995-96 y también con el hecho de que el modelo ha tenido fuerte presencia en zonas intraurbanas donde el suelo tiende a ser más caro y escaso. La evolución del proceso exige un ejercicio de periodización encaminado a descubrir los ciclos y la propia diversidad interna del fenómeno. También suena lógico suponer un sobredimensionamiento

6Seconsideraron solamente los de gran superficie, quea su vez representan a los estratos sociales altos, a diferencia del trabajo delckx(2000), quehace un inventario que intenta ser exhaustivo e involucra unidades pequeñas, muchas de ellas representativas de los estratos medios y medios-bajos. Bajo este criterio lleva a identificar218unidades.

7 Unelemento que puede explicarla disminución de superficies es de orden legal: elNuevoCódigo Civil delEstadodeJ alisco, vigentedesde 1995, estableceensu art́́culo 1005 que ‘todo condominio, simple o compuesto, tendrá una extensión máxima de diez hectáreas o una población que no exceda de dos mil quinientos habitantes"(1995:194). 
Segregaciónresidencialyfragmentación urbana

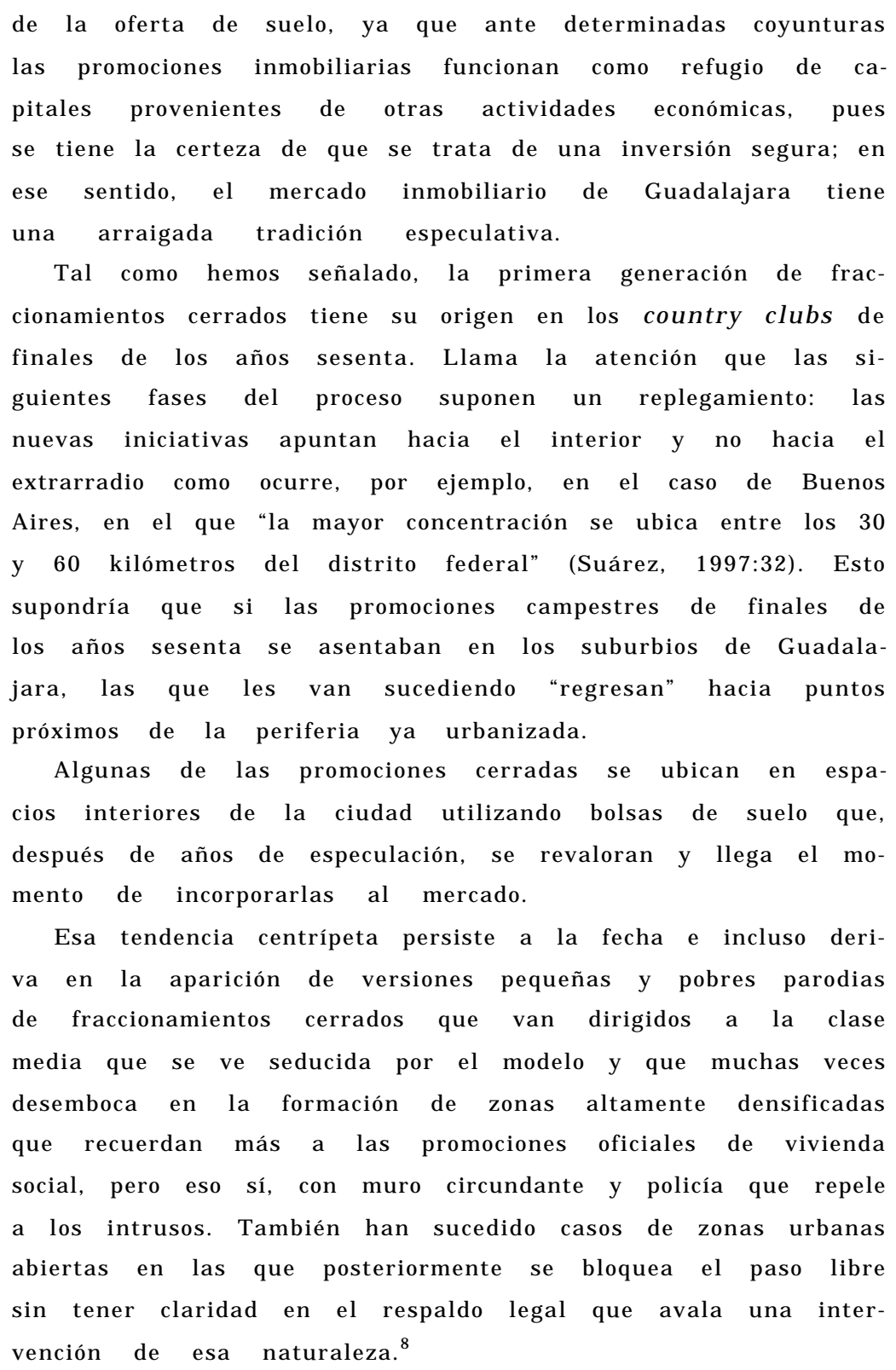

8Estetipo derespuesta se ha presentado en Guadalajara, aunquetiene mayor impacto en ciudades como México, Buenos Aires y Santiago deChile. 
El esquema espacial que hemos dibujado tiene el mérito de la síntesis, pero requiere de matices. En el aspecto estructural debemos tomar en cuenta que el fenómeno no crece en forma constante, lineal y homogénea. $Y$ no lo hace pues coincide con un período (1970-2000) en el que la economía del país observa grandes sobresaltos y crisis económicas recurrentes que necesariamente impactan un sector tan sensible como es el inmobiliario. Ante ese escenario de inestabilidad es común que la edificación resulte mucho más lenta que la capacidad para ofrecer y comercializar suelo, lo que supondría que éste tiende a quedar ocioso por largos periodos.

Por otro lado es inadecuado hablar de la relación centroperiferia en términos geométricos como si se tratara de un espacio en blanco. A pesar de que la Zona Conurbada de Guadalajara ha dibujado una trama más o menos concéntrica presenta una serie de "rugosidades" que, para el tema que nos interesa, referiremos a dos aspectos: los sectores de la ciudad que desde el punto de vista simbólico son altamente codiciados para residir y la presencia física de "externalidades positivas" entre las que destaca la presencia de bosques y la articulación con vías rápidas de circulación.

Bajo estas consideraciones logra perpetuarse el modelo de segregación que en su momento fue apoyado por "las colonias" de principios del siglo xx y la Colonia Chapalita a partir de la década de 1940: los fraccionamientos cerrados siguen la tradición-poniente destacando el municipio de Zapopan y se aferran en primer lugar a uno de los principales ejes de salida y acceso de la ciudad (la carretera a Morelia) que coincide con un espacio de alta calidad ambiental: el Bosque de la Primavera sobre el que se sitúan Bugambilias y El Palomar, dos de los fraccionamientos cerrados más conocidos e identificables visualmente, ya que algunos de sus sectores se emplazan sobre terrenos en ladera.

Ambos surgen a principios de los años setenta (1975 y 1972 respectivamente) y se sitúan como los más extensos de 
Segregaciónresidencialyfragmentación urbana

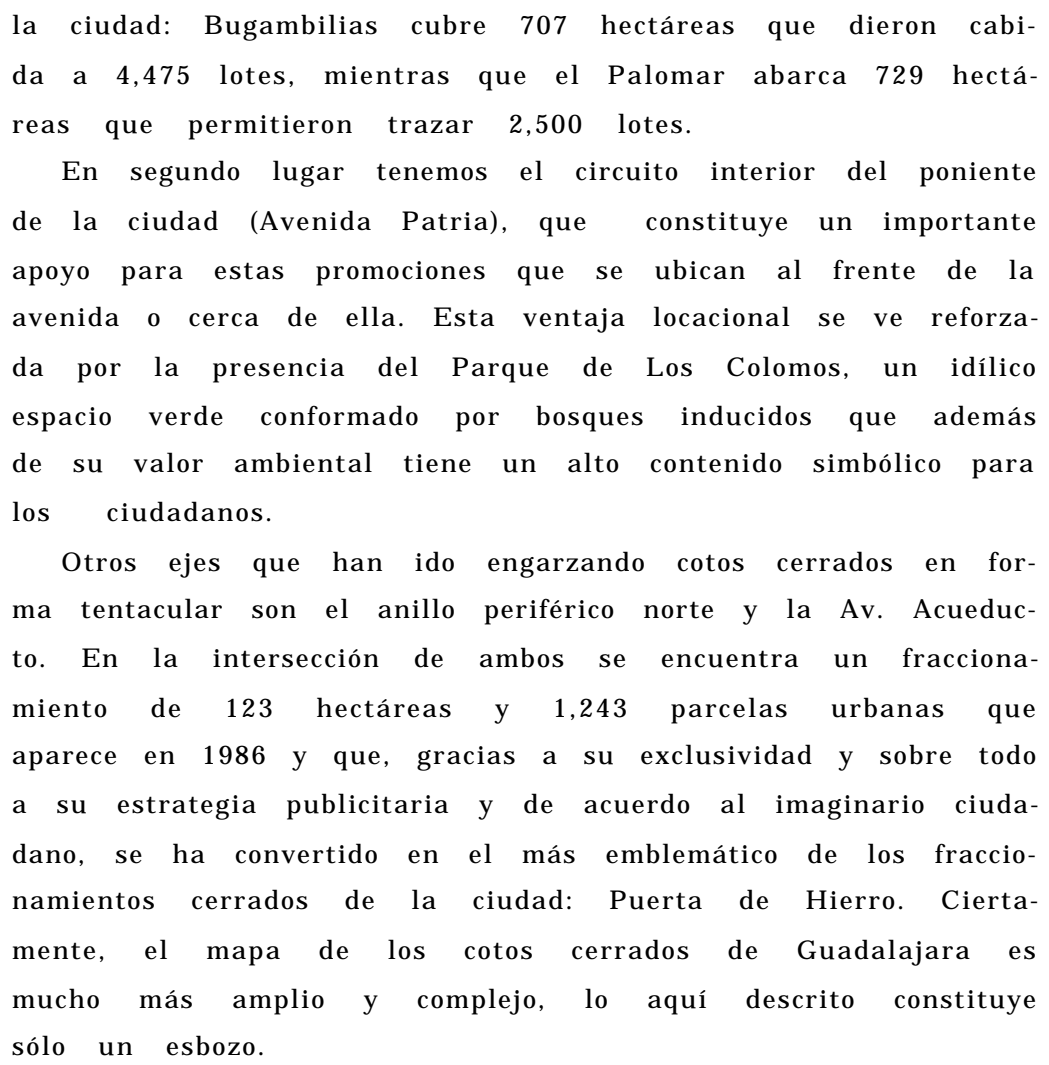

\section{Algunas claves para estudiar los cotos cerrados}

Consideramos que las múltiples lecturas que pueden hacerse de los fraccionamientos cerrados deben tomar en cuenta, entre otros, los siguientes aspectos claves.

- Las estrategias de los promotores inmobiliarios. Este tema es relevante, ya que los promotores son corresponsables en la introducción y desarrollo del modelo. Su estudio puede involucrar múltiples dimensiones: una de las más atractivas es el análisis del discurso publicitario, puesto que mediante éste se crean imágenes y se alimen- 
ta el concepto de exclusividad y por tanto el de segregación. Los promotores y corredores inmobiliarios generalmente usan canales formales muy visibles, como son secciones periodísticas, revistas especializadas, grandes carteles publicitarios e Internet. Así, por ejemplo, el diario El Clarín de Buenos Aires publica la sección especializada Countries, en la que se incluye una "hoja de ruta", como se llama a un plano en el que aparecen señalados 217 barrios cerrados y 95 countries, así como una serie de anuncios en los que se pueden leer eslogans como "Un lugar para soñar", "Vivir seguro y en contacto con la naturaleza es posible" (El Clarín, 21 de agosto de 1999, Buenos Aires). Para el caso de Guadalajara existen revistas de propaganda inmobiliaria, entre las que destaca Casas y terrenos, publicación mensual donde es posible consultar la oferta disponible. Aquí encontramos mensajes como "El privilegio de vivir por arriba de los demás", "Lujo y seguridad", "Plusvalía y seguridad", "El lugar para soñar despierto". Este tipo de mensajes sirven de vehículo para la difusión de los valores que respaldan estas promociones y contribuyen a construir formas específicas de entender la ciudadanía y a perfilar una conciencia de clase.

- La acción y postura del Estado. Si bien los promotores privados constituyen un agente básico en el fenómeno estudiado, es bueno recordar que la conducción del proceso de urbanización es un asunto de Estado. Sus competencias abarcan los tres niveles de gobierno (federal, estatal y municipal) y cubren desde la incorporación de suelo rústico a la ciudad hasta la prestación de servicios públicos. Lo anterior implica una serie de instrumentos legales que pueden avalar la legitimidad jurídica de las distintas formas de producir ciudad. En el caso de Jalisco no existe una postura explícita sobre los fraccionamientos cerrados. La vigente Ley de Desarrollo Urbano del Estado de J alisco no hace referencias a los fraccionamientos cerrados como

\section{6}


Segregaciónresidencialyfragmentación urbana

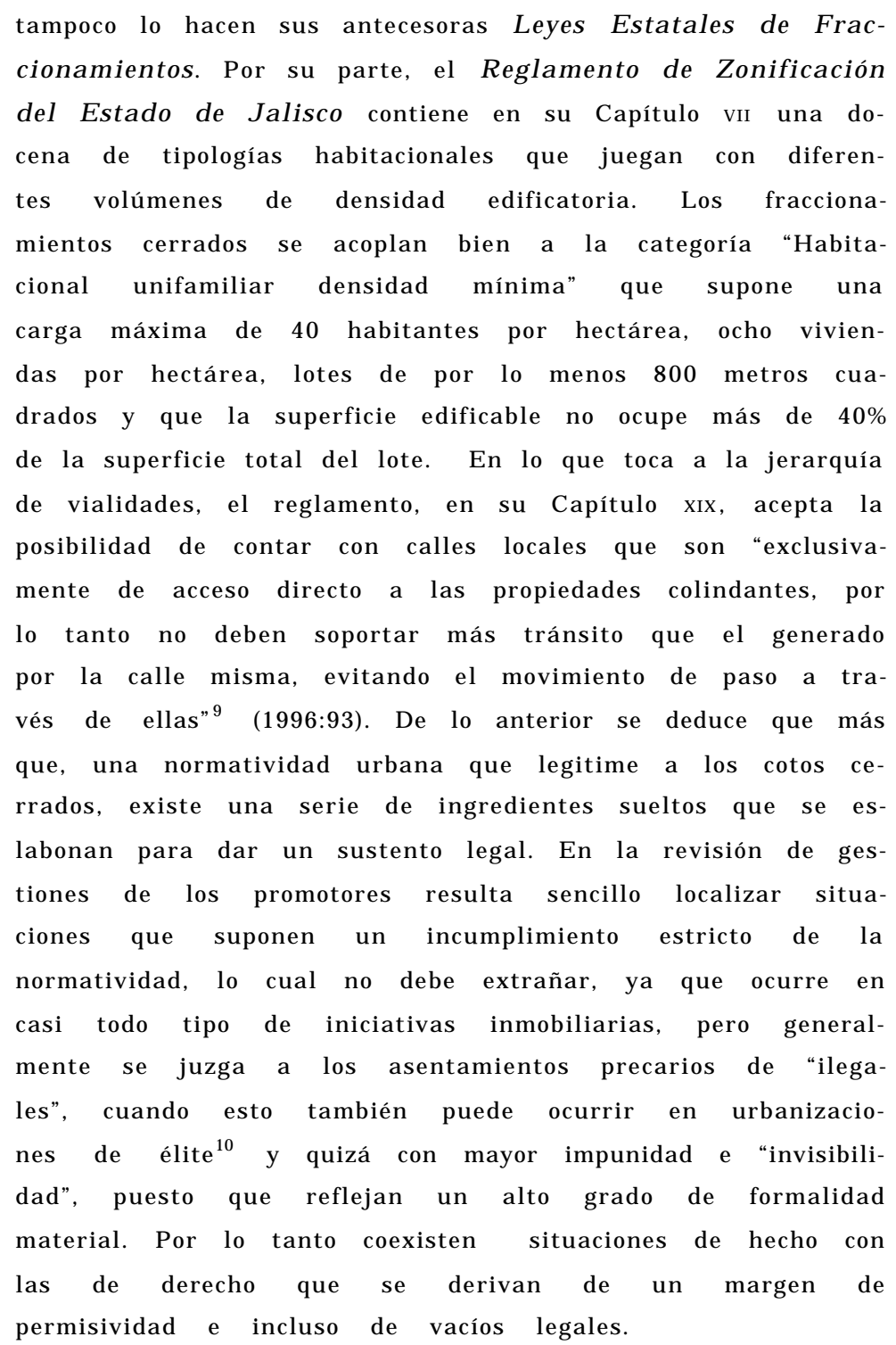


- Impacto urbano y análisis de costos y beneficios. Independientemente del grado de legalidad, el modelo de los fraccionamientos cerrados puede resultar legítimo para los promotores y usuarios de esos espacios. También es perfectamente entendible que resuelva problemas que el Estado no puede enfrentar y por lo tanto se magnifiquen sus beneficios. Los organismos de planeación urbana y la propia ciudadanía deberían hacer un ejercicio de evaluación de costos y beneficios que esta modalidad urbana supone para la ciudad en su conjunto. Se puede argumentar, por ejemplo, que genera espacios de alta calidad ambiental que permiten la infiltración de agua e incrementan la masa forestal, lo cual genera beneficios indirectos para toda la ciudad. Pero al mismo tiempo dificultan la circulación vehicular puesto que los largos muros cerrados entorpecen la fluidez vial y obligan a realizar trayectos más prolongados con el consiguiente gasto en tiempo y energía. Esto último contribuye a disminuir la calidad del aire e incrementa la temperatura. No cabe duda que la expansión de este tipo de espacios puede resultar cómoda para el Estado desde el momento en que "se desentiende" de una parte de la ciudad, pero también se necesita evaluar sus efectos sobre la fiscalidad municipal. Otra dimensión interesante es su impacto sobre la formación de precios del suelo. En la medida en que generan valores que se sitúan en la cúspide (el precio del suelo no edificado llega a superar los 300 dólares por metro cuadrado) contribuyen a generar un efecto inflacionario que impacta directa o indirectamente al conjunto urbano.

\section{Epílogo: construirpuentes,} no sólo murallas

El fenómeno de los fraccionamientos cerrados es por demás complejo. Además de permitir una lectura sobre las nue-

\section{8}




\section{Segregaciónresidencialyfragmentaciónurbana}

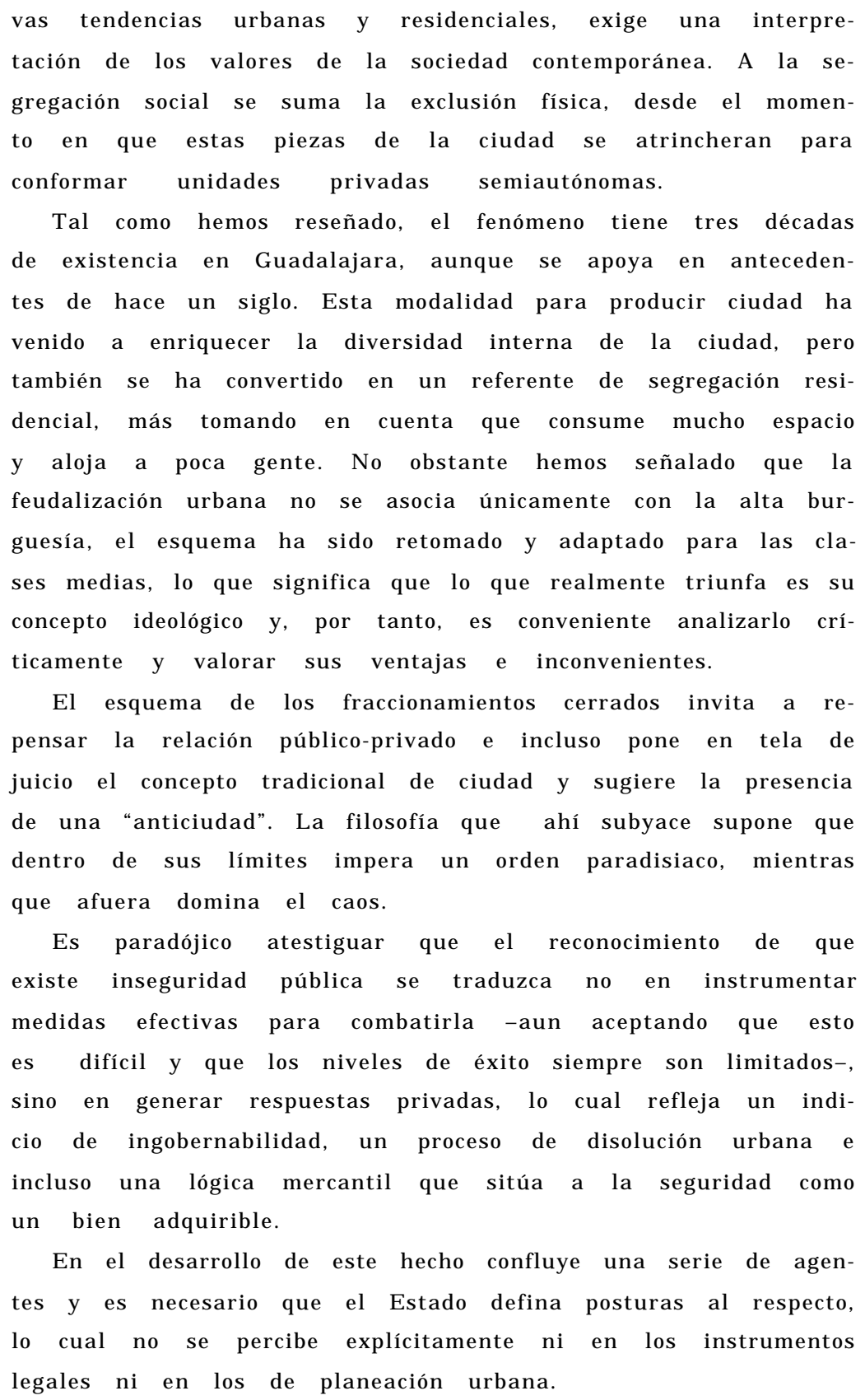

Tal como hemos reseñado, el fenómeno tiene tres décadas de existencia en Guadalajara, aunque se apoya en antecedentes de hace un siglo. Esta modalidad para producir ciudad ha venido a enriquecer la diversidad interna de la ciudad, pero también se ha convertido en un referente de segregación residencial, más tomando en cuenta que consume mucho espacio y aloja a poca gente. No obstante hemos señalado que la feudalización urbana no se asocia únicamente con la alta burguesía, el esquema ha sido retomado y adaptado para las clases medias, lo que significa que lo que realmente triunfa es su concepto ideológico $y$, por tanto, es conveniente analizarlo críticamente y valorar sus ventajas e inconvenientes.

El esquema de los fraccionamientos cerrados invita a repensar la relación público-privado e incluso pone en tela de juicio el concepto tradicional de ciudad y sugiere la presencia de una "anticiudad". La filosofía que ahí subyace supone que dentro de sus límites impera un orden paradisiaco, mientras que afuera domina el caos.

Es paradójico atestiguar que el reconocimiento de que existe inseguridad pública se traduzca no en instrumentar medidas efectivas para combatirla -aun aceptando que esto es difícil y que los niveles de éxito siempre son limitados-, sino en generar respuestas privadas, lo cual refleja un indicio de ingobernabilidad, un proceso de disolución urbana e incluso una lógica mercantil que sitúa a la seguridad como un bien adquirible.

En el desarrollo de este hecho confluye una serie de agentes $y$ es necesario que el Estado defina posturas al respecto, lo cual no se percibe explícitamente ni en los instrumentos legales ni en los de planeación urbana. 


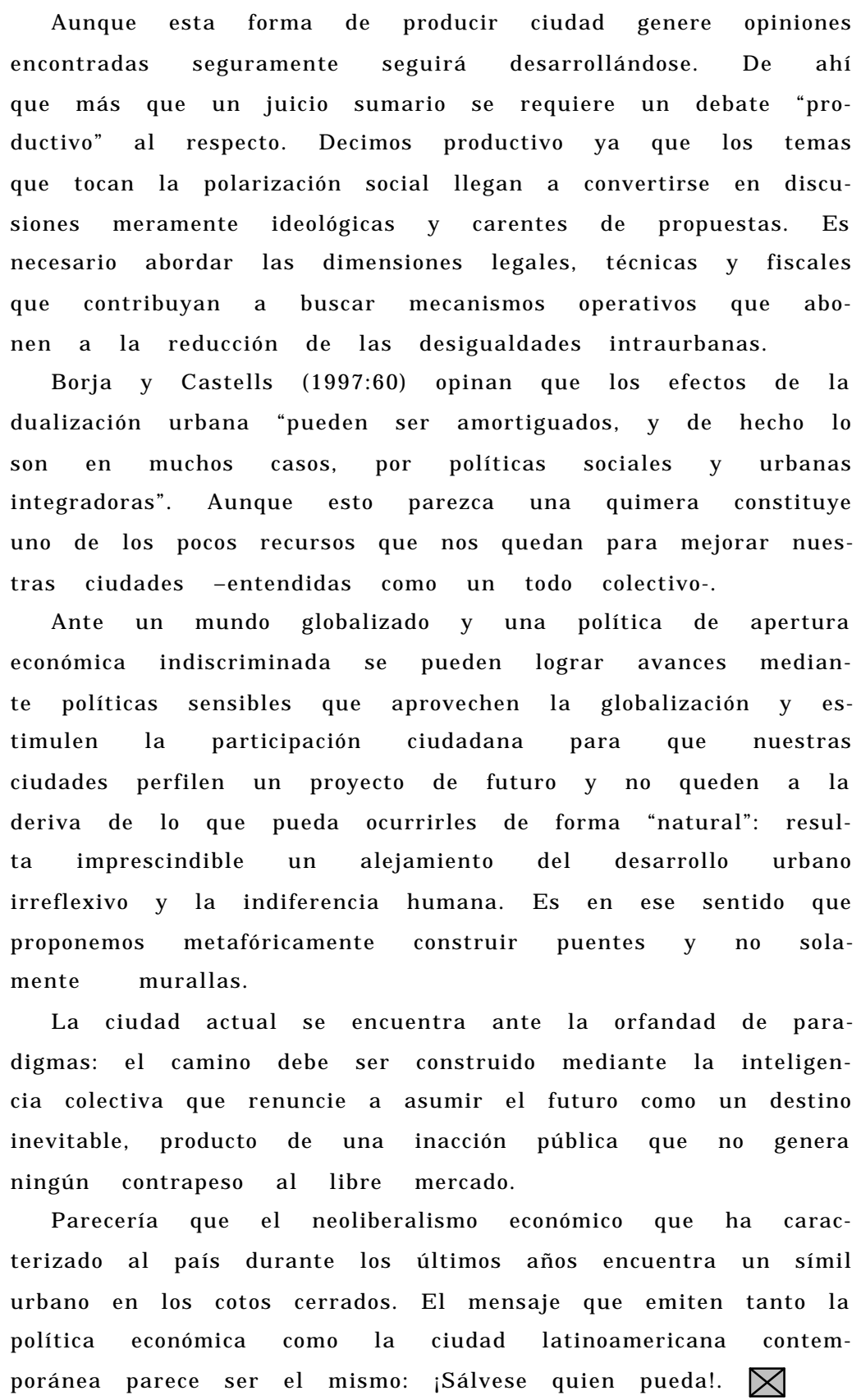


Segregaciónresidencialyfragmentaciónurbana

Amendola, Giandomenico (2000). La ciudad posmodema. Magiay miedo de la metrópolis contemporánea, CelesteEdiciones, Madrid, p. 379 .

BlakelyEduard] . y Mary Gail Snyder(1997). Fortress America, gated communities in the United States, Brookings Institution, Washington.

Borja, J ordi y Manuel Castells (1997).Local y Global. La gestión de las ciudades en la eradela información Editorial Taunus, Madrid, p. 418.

Caldeira, Teresa (1996). "Un noveau modéle de ségrégation spatiale: les murs deSao Paulo", en Revie Intemationale des Sciences Sociales, No. 147, Pańs.

- (1999). "Fortified enclaves: the new urban segregation", en $J$ ames Holston (Ed.), Cities and citizenship, Duke University Press, Durhamy Londres.

Congreso del Estado deJ alisco (1995). Nuevo código civil del Estado deJ alisco, Guadalajara, México, p. 568.

Davis, Mike (1990). City of Quart, Excavating the future in Los Angeles, Vintage Books, NewYork, 1992.

Frugoli, Heitor (1995). Sao Paulo: espacos publicos e interacao social, Sao Paulo, Marco Zero-SESC.

García Canclini, Nestor (1999).La globalización imaginada, Editorial Paidós, México, D.F., p. 238.

Gobiemo del Estado deJ alisco (1969). 'Ley Estatal de Fraccionamientos". Publicada en el Diario Oficial del Estado el día 13 de febrero de 1969, Guadalajara, México.

- (1996). Ley de Desarrollo Urbano del Estado deJ alisco, Guadalajara, México, p. 90.

- (1996). Reglamento deZonificación del Estado deJ alisco, Guadalajara, México, p. 150.

Gómez Serrano, J esús, Calixto Sema Valdivia y Marco Alejandro Sifuentes (1998). El desarrollo histórico de la vivienda enAguascalientes, Instituto de Vivienda de Aguascalientes, Gobiemo del Estado deAguascalientes, p. 215.

Ickx, Wonne (2000). "Los fraccionamientos cerrados en la Zona Metropolitana de Guadalajara". Tesis de Maestría en Ciencias de la Arquitectura, Programa en Urbanismo y Desarrollo, Centro de Estudios Metropolitanos, CUAAD, Universidad de Guadalajara, p. 107.

INEGI(2000).XII Censo General de Población y Vivienda, Resultados Preliminares, Aguascalientes, p. 375.

Sociedad $\bigotimes$ No. 20 
Bibliografía Kowarick, Lucio (1992). "Investigación urbana y sociedad: comentanios sobre nuestra América", en Sociológica No. 18, Universidad Autónoma Metropolitana, Unidad Azcapotzalco, México, D.F., pp. 11-27.

Lacarrieu, Mónica (1998). 'El dilema de lo local y la producción social de la feudalización", en Alteridades, No. 15, Universidad Autónoma Metropolitana, Unidad Ixtapalapa, Departamento deAntropología, México, D.F., pp. 7-23.

Landa, Roberto (2000). “Consecuencias demográficas de las nuevas urbanizaciones privadas en el conurbano bonarense. El caso de Pilar, en la década del 90", II Encuentro Humboldt, Mar del Plata, Argentina (en prensa).

Lechner, Norbert(1988). "Un desencanto llamado posmodemismo", en Punto de Vista, No. 33, Buenos Aires, pp. 9-12.

López Moreno, Eduardo (1996).La vivienda social: una historia.Red Nacional de Investigación Urbana, Universidad de Guadalajara, p. 507.

McKenzie, Evan (1994).Privatopia: homeownerassociations and the nise of residential privategovemment, Nueva Haven, Yale UniversityPress.

Peñaloza, PedroJ oséy FelipeEspinosa-Torres (2000). 'Los desafíos de la prevención del delito en América Latina”, enEste País, No. 116, México, D.F., pp. 2-13.

Pesci Rubén (1996). “¿Barios cerrados o ciudad abierta?”, EnCiur dady Teritorio, Estudios Temitoriales, No. 110, Ministerio de Fomento, Madrid, pp. 823-824.

PrévotSchapira, Marie-France (2000). “América Latina: la ciudad fragmentada", en Revista de Occidente, No. 230-231, Fundación J osé Ortega y Gasset, Madrid, pp. 25-46.

Residentes de Chapalita, A.C. (1993).La colonia Chapalita en la participación ciudadana de Guadalajara y Zapopan Documento que incluyeun resumen de sus estatutos. Guadalajara, México, p. 22 (mimeografiado).

Safa, Patricia (1999). 'Construir mundos, levantar muros y preservar patrimonio: ¿ una altemativa de vida en las grandes ciudades?. Condominios y fraccionamientos cerrados en la ciudad de México", CIESAS-Occidente, Guadalajara, p. 29 (inédito).

Segre, Roberto (1998). "Río deJ aneiro. Símbolos urbanos: centralidad y poder, periferia y comunidad", en Ciudad y Teritorio, Estur dios Temitoriales, No. 118, Ministerio de Fomento, Madrid, pp. 697-708. 
Segregaciónresidencialyfragmentaciónurbana

Silva, Armando (1992). Imaginarios urbanos. BogotáySao Paulo: cultur Bibliografía ra y comunicación urbanaenAmérica Latina, TercerMundo Editores, Bogotá.

Suárez, Francisco (1997). 'Nuevas tendencias residenciales en la ciudad de Buenos Aires", en Carta Económica Regional, No. 52, Instituto de Estudios Económicos y Regionales, Universidad de Guadalajara, pp. 31-38.

Tella, Guillermo Carlos (2000). “Acerca de la cuestión pos-urbana: modalidades de apropiación reciente del espacio metropolitano de Buenos Aires". II Encuentro Intemacional Humboldt, Mar del Plata, Argentina (en prensa).

Valladares, Licia y Martine J acot(1999). "Las rejas de la otra Brasilia”, enUNESCO, elcorreo, junio de 1999, Pańs, Francia, pp. 29-31. 